\title{
Spotlighting risk factors for severe acute malnutrition under 5 years: a case control study
}

\author{
Hegde $S^{1}$, Gaur $\mathbf{A}^{2}$ \\ ${ }^{1}$ Dr Shruti T Hegde, Senior Resident, ${ }^{2}$ Dr Ajay Gaur, Professor \& HOD, both authors are affiliated with Department of \\ Pediatrics, GRMC, Gwalior, MP, India.
}

Address for Correspondence: Dr Shruti T Hegde, Email: shrutihegde29@gmail.com

\begin{abstract}
Objective: Malnutrition remains one of the most common causes of morbidity and mortality among children throughout the world. W.H.O. has defined Severe and Moderate acute Malnutrition (SAM, MAM) as per specific criteria and there are specific guidelines for better inpatient management of SAM children. Unfortunately, there is not much literature on modifiable risk factors which not only govern the causation but have large impact on prognosis. This study is an attempt to understand and prioritize modifiable risk factors in SAM. Methods: This is a prospective observational case control study with 200 subjects conducted at a tertiary care hospital after taking written informed consent. A total of 100 cases were enrolled who were children between 6 months to 59 months with severe acute malnutrition (diagnosed as per WHO criteria). The 100 controls chosen were age matched children with weight for height >-2SD admitted for other causes. Data regarding birth, maternal education, feeding practices, socio-demographic parameters, immunization, past illnesses and detailed anthropometric measurements were compared by statistical analysis using SPSS package (version 17.0). Result: A total of 100 cases and 100 controls were enrolled. Out of which $65 \%$ cases were below 2 years and $59 \%$ of controls were between 2-5years. The study showed that following variables had independent association with severe acute malnutrition: age $<2$ years, low birth weight, birth order $>3$, younger age of mother at conception, prelacteal feeds, top feeds, delayed initiation of complementary feeds, and partial immunization. Conclusion: The present study helps to identify significant risk factors associated with severe acute malnutrition which can be of help in deciding preventive measures, management and policy making in future.
\end{abstract}

Keywords: Severe acute malnutrition, Risk factors, mortality.

\section{Introduction}

Severe malnutrition among children under five years of age remains a major embarrassment and impediment to optimal human capital development in India. Malnutrition remains one of the most common causes of morbidity and mortality among children throughout the world. Childhood is a significant stage of life and deprivation during this period can have a long-term adverse impact on the wellbeing of children.

Reduction in infant and child mortality is likely the most important of the millennium development goals (MDG), as children are the most important assets of a nation. Under nutrition consisting of stunting, wasting, and deficiencies of vitamin A and zinc, along with sub optimum breastfeeding, underlies nearly 3.1 million

Manuscript received: $4^{\text {th }}$ February 2017

Reviewed: $11^{\text {th }}$ February 2017

Author Corrected: $18^{\text {th }}$ February 2017

Accepted for Publication: 25 ${ }^{\text {th }}$ February 2017 deaths of children younger than 5 years annually worldwide, representing about $45 \%$ of all deaths in this group [1]. Despite being the second fastest growing economy in the world, India continues to harbor some of the worst social sector indicators. India has the highest burden of child malnutrition in the world, the NFHS 3 data shows 19.8 per cent of Indian U5s children as wasted, where as NFHS 4 (2015-16) shows 25.8 per cent in Madhya Pradesh and 6.4 per cent in country, 9.2 percent in MP (NFHS 4) of U5s children as severely wasted. In terms of numbers this would translate to almost astounding 8 million children in India who are severely wasted out of the 25 million children who are wasted [2].

The child prevalence of malnutrition in India is twice that of Sub-Saharan Africa and more than one third of the world's children who are wasted live in India. There 
has been uneven progress in the reduction of malnutrition in India, in terms of regional variations. In spite of such astounding figures the number of studies identifying the prevalence of SAM and its risk factors in India are minimal. The present study is an attempt to identify the risk factors leading to severe malnutrition and prioritize them, thereby helping in identifying children who will be at a higher risk for development of severe acute malnutrition.

\section{Methods}

This case control study was conducted at the malnutrition unit of a tertiary care hospital over a period of one year. The cases for the study were children of either gender with severe acute malnutrition (SAM) aged between 6 months to 59 months admitted at our hospital for various reasons. A case of SAM was diagnosed based on WHO criteria, weight for length/height <-3SD as per WHO 2006 growth standards, mid upper arm circumference $<115 \mathrm{~mm}$, bilateral pedal edema and visible severe wasting [3]. The controls were age matched children with weight for height $>-2 \mathrm{SD}$, admitted for other medical conditions. Children with congenital malformations and chronic illness were excluded from the study. Approval was obtained from the ethical committee. Written informed consent was obtained from the parents of the subjects. The cases and controls had to undergo appetite test at the time of admission and testing for urine ketone bodies. Then they were evaluated based on a questionnaire regarding their birth history, maternal education, feeding history including complementary feeding, immunization status, socio economic factors, past illness and detailed anthropometric measurements along with general and systemic examination.

Statistical analysis was performed using the SPSS statistical package (version 17.0). Categorical variables are presented as absolute numbers and percentage and were compared using Chi-square. Fishers exact test was used if expected frequencies $<5$. To identify potential factors associated with severe malnutrition in children, univariate analyses was performed. Multivariate logistic regression model was used to identify independent risk factors for severe acute malnutrition in children aged up to 5 yrs. Unadjusted Odds ratio, adjusted odds ratio and its $95 \%$ CI were also calculated and presented in the corresponding tables. For all statistical tests, a $\mathrm{p}$ value $<$ 0.05 was taken to indicate a significant difference.

\section{Results}

In this study, a total of 200 subjects were enrolled, out of which 100 were cases (61 females and 39 males) and 100 were taken as controls (56 females and 44 males).

Table No-1: General characteristics and birth factors.

\begin{tabular}{|c|c|c|c|c|c|c|c|}
\hline \multirow[t]{2}{*}{ Characteristics } & \multicolumn{2}{|c|}{ Controls $(n=100)$} & \multicolumn{2}{|c|}{ Cases $(n=100)$} & \multirow{2}{*}{$\begin{array}{l}\text { Unadjusted } \\
\text { Odds Ratio }\end{array}$} & \multirow{2}{*}{$95 \% \mathrm{CI}$} & \multirow{2}{*}{ P Value } \\
\hline & $\mathbf{n}$ & $\%$ & $\mathbf{n}$ & $\%$ & & & \\
\hline \multicolumn{8}{|l|}{ Age (yrs) } \\
\hline$<2$ yrs & 41 & $41.0 \%$ & 65 & $65.0 \%$ & 2.673 & $1.508-4.737$ & \multirow{2}{*}{0.001} \\
\hline $2-5 \mathrm{yrs}$ & 59 & $59.0 \%$ & 35 & $35.0 \%$ & Ref & & \\
\hline \multicolumn{8}{|l|}{ Sex } \\
\hline $\mathrm{F}$ & 56 & $56.0 \%$ & 61 & $61.0 \%$ & 1.229 & $0.669-2.159$ & \multirow{2}{*}{0.473} \\
\hline $\mathrm{M}$ & 44 & $44.0 \%$ & 39 & $39.0 \%$ & Ref & & \\
\hline \multicolumn{8}{|l|}{ Birth weight } \\
\hline$<2.5 \mathrm{Kg}$ & 22 & $22.0 \%$ & 53 & $53.0 \%$ & 3.998 & $2.162-7.394$ & \multirow{2}{*}{$<0.001$} \\
\hline$>2.5 \mathrm{Kg}$ & 78 & $78.0 \%$ & 47 & $47.0 \%$ & Ref & & \\
\hline \multicolumn{8}{|l|}{ Gestational Age } \\
\hline Preterm & 6 & $6.0 \%$ & 20 & $20.0 \%$ & 3.875 & $1.484-10.121$ & $<0.001$ \\
\hline Term & 93 & $93.0 \%$ & 80 & $80.0 \%$ & Ref & & $<0.001$ \\
\hline Post Term & 1 & $1.0 \%$ & 0 & $0.0 \%$ & - & - & 1.000 \\
\hline \multicolumn{8}{|l|}{ Birth Order } \\
\hline $1-2$ & 85 & $85.0 \%$ & 51 & $51.0 \%$ & Ref & & \\
\hline $3-4$ & 15 & $15.0 \%$ & 46 & $46.0 \%$ & 5.111 & $2.594-10.072$ & $<0.001$ \\
\hline$>4$ & 0 & $0.0 \%$ & 3 & $3.0 \%$ & 0.0862 & $0.026-0.289$ & 0.246 \\
\hline
\end{tabular}


Among them, $65 \%$ of the cases were $<2$ years of age and $59 \%$ of the controls were 2 to 5 years of age (p<0.001). Out of the 100 cases, 5 presented with oedematous malnutrition.

The parameters that were compared between cases and controls included: birth history, maternal factors, dietary factors including complementary feeding, appetite test, immunization status, socio economic characteristics, past illness history, anthropometry, general with physical examination and these included a total of 38 variables. In birth history it was found that children with SAM had 3.9 times higher chance of weighing $<2500 \mathrm{~g}$ at birth and 3.8 times chance of being born preterm (Table no 1).

Table No-2: Dietary factors.

\begin{tabular}{|c|c|c|c|c|c|c|c|}
\hline \multirow[t]{2}{*}{ Characteristics } & \multicolumn{2}{|c|}{ Controls $(n=100)$} & \multicolumn{2}{|c|}{ Cases $(n=100)$} & \multirow{2}{*}{$\begin{array}{l}\text { Unadjusted } \\
\text { Odds Ratio }\end{array}$} & \multirow[t]{2}{*}{$95 \% \mathrm{CI}$} & \multirow[t]{2}{*}{ P Value } \\
\hline & $\mathbf{n}$ & $\%$ & $\mathbf{N}$ & $\%$ & & & \\
\hline \multicolumn{8}{|l|}{ Prelacteal feeds } \\
\hline Given & 12 & $12.0 \%$ & 39 & $39.0 \%$ & 4.688 & $2.271-9.679$ & \multirow[t]{2}{*}{$<0.001$} \\
\hline Not Given & 88 & $88.0 \%$ & 61 & $61.0 \%$ & Ref & & \\
\hline \multicolumn{8}{|l|}{$\begin{array}{c}\text { Time of Initiation of } \\
\text { BF(TIBF) }\end{array}$} \\
\hline Within $1 \mathrm{hr}$ & 69 & $69.0 \%$ & 13 & $13.0 \%$ & Ref & & \multirow[t]{2}{*}{$<0.001$} \\
\hline After $1 \mathrm{hr}$ & 31 & $31.0 \%$ & 87 & $87.0 \%$ & 14.896 & $\begin{array}{l}7.246- \\
30.621\end{array}$ & \\
\hline \multicolumn{8}{|l|}{ Duration of EBF } \\
\hline$<$ or $=$ to 6 months & 98 & $98.0 \%$ & 71 & $71.0 \%$ & Ref & & \multirow[t]{2}{*}{$<0.001$} \\
\hline$>6$ months & 2 & $2.0 \%$ & 29 & $29.0 \%$ & 20.141 & $\begin{array}{l}4.624- \\
86.622\end{array}$ & \\
\hline \multicolumn{8}{|l|}{ Top feeds } \\
\hline Given & 5 & $5.0 \%$ & 60 & $60.0 \%$ & 28.500 & $\begin{array}{c}10.651- \\
76.263\end{array}$ & \multirow[t]{2}{*}{$<0.001$} \\
\hline Not Given & 95 & $95.0 \%$ & 40 & $40.0 \%$ & Ref & & \\
\hline \multicolumn{8}{|l|}{ Type of top feeds } \\
\hline Animal milk & 3 & $3.0 \%$ & 58 & $58.0 \%$ & 19.333 & $\begin{array}{l}1.982- \\
188.60\end{array}$ & \multirow[t]{2}{*}{$<0.001$} \\
\hline Formula milk & 2 & $2.0 \%$ & 2 & $2.0 \%$ & Ref & & \\
\hline \multicolumn{8}{|l|}{ Method of top feeds } \\
\hline Bottle fed & 0 & $0.0 \%$ & 22 & $22.0 \%$ & Ref & & \multirow[t]{2}{*}{$<0.001$} \\
\hline Spoon fed & 5 & $5.0 \%$ & 38 & $38.0 \%$ & - & - & \\
\hline \multicolumn{8}{|l|}{ Initiation of $\mathbf{C F}$} \\
\hline 6-9 months & 99 & $99.0 \%$ & 21 & $21.0 \%$ & Ref & & \multirow{3}{*}{$<0.001$} \\
\hline 10-12 months & 1 & $1.0 \%$ & 53 & $53.0 \%$ & 249.860 & $\begin{array}{l}32.695- \\
1909.43\end{array}$ & \\
\hline$>12$ months & 0 & $0.0 \%$ & 24 & $24.0 \%$ & - & - & \\
\hline \multicolumn{8}{|l|}{ Consistency of CF } \\
\hline Adequate & 100 & $100.0 \%$ & 9 & $9.0 \%$ & Ref & & \multirow{2}{*}{$<0.001$} \\
\hline Inadequate & 0 & $0.0 \%$ & 91 & $91.0 \%$ & - & - & \\
\hline \multicolumn{8}{|l|}{ Calorie content of $\mathrm{CF}$} \\
\hline$<50 \%$ of required & 0 & $0.0 \%$ & 66 & $66.0 \%$ & - & - & \multirow{3}{*}{$<0.001$} \\
\hline $50-80 \%$ of required & 22 & $22.0 \%$ & 32 & $32.0 \%$ & - & - & \\
\hline$>80 \%$ of required & 78 & $78.0 \%$ & 0 & $0.0 \%$ & Ref & & \\
\hline
\end{tabular}

Among maternal factors it was found that age of marriage $<19$ years $(\mathbf{O R}=\mathbf{3 . 8 4}, \mathbf{p}<\mathbf{0 . 0 0 1})$ and maternal illiteracy $(\mathbf{p}<\mathbf{0 . 0 0 1})$ had significantly higher association with SAM. Coming to dietary factors, prelacteal feeds $(\mathbf{O R}=\mathbf{4 . 6 8 8}$, 
$\mathbf{p}<\mathbf{0 . 0 0 1})$, initiation of breast feeding after 1 hour $(\mathbf{O R}=\mathbf{1 4 . 8 9}, \mathbf{p}<\mathbf{0 . 0 0 1})$, reduced duration of exclusive breast feeding and giving top feeds $(\mathbf{O R}=\mathbf{2 8 . 5}, \mathbf{p}<\mathbf{0 . 0 0 1})$ had significantly higher association with SAM (Table no 2). In complementary feeding it was the delayed initiation of feeds $(\mathbf{O R}=\mathbf{2 4 9 . 8}, \mathbf{p}<\mathbf{0 . 0 0 1})$ and calorie content $<50 \%$ of required were significantly associated with SAM.

The risk of being partially immunized was 64.4 times higher in children with SAM. Among the socio economic characteristics, child spacing $<3$ years $(\mathbf{O R}=\mathbf{3 2}, \mathbf{9 5} \% \mathbf{C I}=\mathbf{1 1 . 6 - 8 8 . 2})$, socio economic status (according to modified Kuppuswamy classification) falling below class IV, open field defecation and overcrowding were significantly associated with SAM. It was also found that children with SAM had $>3$ to 5 episodes of illness in a year which were mainly acute watery diarrhoea, and $99 \%$ of the cases had inadequate feeding during illness $(\mathbf{p}<\mathbf{0 . 0 0 1})$.

Table No-3: Prioritizing factors using Multivariate Logistic Regression (Stepwise Method).

\begin{tabular}{|c|c|c|c|}
\hline Characteristics & Adjusted Odds Ratio & $95 \% \mathrm{CI}$ & $P$ value \\
\hline \multicolumn{4}{|l|}{ General Characteristics } \\
\hline Age $($ yrs $)(<2$ yrs $)$ & 2.072 & $1.093-3.931$ & 0.026 \\
\hline Birth weight $(<2.5 \mathrm{Kg})$ & 3.242 & $1.667-6.307$ & 0.001 \\
\hline Birth Order $(3-4)$ & 4.721 & $2.318-9.616$ & $<0.001$ \\
\hline \multicolumn{4}{|l|}{ Maternal Characteristics } \\
\hline Age at 1 st conception $(15-20 \mathrm{yrs})$ & 12.333 & $3.448-44.116$ & $<0.001$ \\
\hline Prelacteal feeds & 10.65 & $2.283-49.675$ & 0.003 \\
\hline Top Feeds (Animal) & 107.643 & $20.272-571.591$ & $<0.001$ \\
\hline CF Initiation (10-12 months) & 5503.947 & $50.644-5014.689$ & $<0.001$ \\
\hline \multicolumn{4}{|l|}{ Immunization } \\
\hline Partially immunized & 64.61 & $25.348-163.682$ & $<0.001$ \\
\hline \multicolumn{4}{|l|}{ Socio economic Characteristics } \\
\hline Water Source (Bore Well) & 22.973 & $2.494-211.622$ & 0.006 \\
\hline Toilet Facility (open field) & 46.405 & $15.175-141.903$ & $<0.001$ \\
\hline
\end{tabular}

Further analysis using multivariate logistic regression (stepwise method) showed the following variables had independent association with SAM: age $<2$ years, birth weight $<2500 \mathrm{~g}$, birth order $>3$, younger age of the mother at conception, prelacteal feeds, top feeds, delayed initiation of complementary feeding, partial immunization as shown in table 3 .

\section{Discussion}

The present study identifies various risk factors which were found to be significantly higher in children with SAM compared to controls. On studying the birth weight and birth order it was found that weight $<2500 \mathrm{~g}$ at birth and birth order $>3$ were significantly associated with SAM which is consistent with findings of earlier studies [3]. On studying the maternal factors, it was found that maternal illiteracy and early age of marriage and conception were independent risk factor for SAM which is consistent with earlier reports $[4,5,6]$. In the present study, it was found that exclusive breast feeding during the first 6 months of life protected against development of SAM. The practice of giving prelacteal feeds, delayed initiation of breast feeding and top feeding especially using diluted animal milk showed significant association with SAM similar to the results of other studies [7, 8]. The present study also showed initiation of complementary feeding after 10 months and using inadequate consistency and $<50 \%$ of required calorie content were important factors leading to SAM, which is consistent with the results of study by Amsalu et al from Ethiopia[7]. On the other hand, studies from China and Kenya have shown that early introduction of $\mathrm{CF}$ before $6 \mathrm{mo}$ of age increased the risk of being underweight $[9,10]$. A study done in India has remarked that the capacity of a weaning diet to prevent malnutrition of infants depends on its nutritional quality as well as its dietary volume [11]. Studies on feeding practices show that the type of complementary feed given is greatly influenced by traditional socio-cultural beliefs and taboos. In most instances, including India, thin gruels like diluted milk, dilute starch-based liquid without good quality protein are favoured as weaning food and semisolids and solids are introduced relatively late [12]. The results of the present study regarding complementary feeding practices reiterates the key message that quality of complementary feeds, especially the energy and protein content of the food introduced is 
probably more vital in influencing the nutritional status of the child, rather than just the time of initiation of $\mathrm{CF}$.

Lack of complete immunization was found to contribute significantly to the occurrence of SAM, which can be explained by the fact that unimmunized children suffer from various infections which retard their growth. The present study also shows low socio economic status, large family size and overcrowding as significant factors associated with SAM which has been validated in various studies [13].

The study also showed significant association between frequent illness ( $>3$ to 5/year) like acute watery diarrhoea and inadequate feeding during illness with SAM, consistent with findings of other studies [14]. There is a vicious cycle between malnutrition and diarrhea. Attacks of diarrhea in malnourished children tend to be more frequent, severe and of longer duration. At the same time, repeated attacks of diarrhea could lead to poor growth and malnutrition.

Funding: Nil, Conflict of interest: None initiated, Perission from IRB: Yes

\section{References}

1. UNICEF, accessed 02 August 2016 http://www. unicef. org/nutrition.html.

2. Bhutta ZA, Das JK, Rizvi A, Gaffey MF, Walker N, Horton S, Webb P, Lartey A, Black RE; Lancet Nutrition Interventions Review Group; Maternal and Child Nutrition Study Group. Evidence-based interventions for improvement of maternal and child nutrition: what can be done and at what cost? Lancet. 2013 Aug3; 382 (9890) :452-77. doi: 10.1016/S01406736 (13) 60996-4. Epub 2013 Jun 6.

3. Kurup PJ, Khandekar R. Low birth weight as a determinant of protein energy malnutrition in "0-5 years" Omani children of South Batinah region, Oman. Saudi Med J. 2004 Aug;25(8):1091-6.

4. Sufiyan MB, Bashir SS, Umar AA. Effect of maternal literacy on nutritional status of children under 5years of age in the Babban-Dodo community Zaria city, Northwest Nigeria. Ann Nigerian Med 2012; 6 (2): 61-64.

5. Appoh L.Y. and Krekling S. Maternal nutritional knowledge and child nutritional status in the Volta Region of Ghana Maternal \& child nutrition, 1: 100110. doi:10.1111/j.1740-8709.2005.00016.

6. Rayhan MI, Khan MSH. Factors causing malnutrition among under five children in Bangladesh. Pak J Nutr. 2006; 5(6):558-562.

7. Amsalu S, Tigabu Z. Risk factors for severe acute malnutrition in children under the age of five: a case control study. Ethiopian Journal of Developmental Health. 2008; 22 (1):21-25.

8. Ghosh S, Shah D. Nutritional problems in urban slum children. Indian Pediatr. 2004 Jul;41(7):682-96.

9. Wang X, Wang Y, Kang C. Feeding practices in 105 counties of rural China. Child Care Health Dev. 2005 Jul; 31(4):417-23.

10. Bloss E, Wainaina F, Bailey RC. Prevalence and predictors of underweight, stunting, and wasting among children aged 5 and under in western Kenya. J Trop Pediatr. 2004 Oct;50(5):260-70.

11. Sajilata G, Singhal RS, Kulkarni PR. Weaning foods: a review of the Indian experience. Food Nutr Bull. 2002 Jun;23(2):208-26.

12. Elizabeth KE. Changing profile of undernutrition and edematous severe acute malnutrition (ESAM). Indian Pediatr. 2012 Oct;49(10):843.

13. Haidar J, Abate G, Kogi-Makau W, Sorensen P. Risk factors for child under-nutrition with a human rights edge in rural villages of North Wollo, Ethiopia. East Afr Med J. 2005 Dec;82(12):625-30.

14. Assis A, et al. Growth faltering in childhood related to diarrhoea: A longitudinal community based study. European Journal of clinical nutrition 2005; 59(11): 1317-1323.

\section{How to cite this article?}

Hegde S, Gaur A. Spotlighting risk factors for severe acute malnutrition under 5 years: a case control study. J PediatrRes.2017;4(02):138-142.doi:10.17511/ijpr.2017.i02.09. 